Research Report

\title{
Effectiveness of the Use of Manual and Electric Toothbrushes and the Effect of Educational Brushing Teeth with Video Animation on OHI-S Children with Down syndrome
}

\author{
Alivy Aulia Az Zahra, Natasha Winona Audrey, Devalna Siwi Ichyana, Tania Saskianti, Seno Pradopo, Sindy \\ Cornelia Nelwan and Masyithah \\ Department of Pediatric Dentistry, \\ Faculty of Dental Medicine, Universitas Airlangga \\ Surabaya - Indonesia
}

\begin{abstract}
Background: Down Syndrome children have better ability in capturing instructions visually. The audio-visual learning method can be applied to Down Syndrome children. Electric toothbrushes were made to make it easier for them to brush their teeth, besides those electric toothbrushes have a handle that is comfortable to hold and control. Purpose: The purpose of this study is to determine the effectiveness of electric and manual toothbrushes on Down Syndrome children OHI-S scores and determine the effect of education on tooth brushing with animated videos on Down Syndrome children OHI-S scores. Methods: Subjects of the study were 34 Down Syndrome children aged 6-19 years in Surabaya, East Java, Indonesia. OHI-S scores were recorded before and after the subjects were educated to brush their teeth with animated videos or dental phantoms. OHI-S scores were also recorded before and after the subjects brushed their teeth using manual toothbrushes or electric toothbrushes. Results: The test results Independent T-test ( $>0.05)$ showed there was no significant difference between tooth brushing using a manual toothbrush and an electric toothbrush to the decline of OHI-S score of Down Syndrome children. The results of the Mann-Whitney statistical test were $p>0.05$, that there was no significant difference in the reduction in OHI-S scores between Down Syndrome children who were educated with animated videos and dental phantoms. Conclusion: There was no significant difference between manual toothbrushes and electric toothbrushes and there was no significant influence of Down Syndrome OHI-S children who were educated with animated videos or dental phantoms.
\end{abstract}

Keywords: animation; down syndrome; education; oral hygiene index

Correspondence: Tania Saskianti, Department of Pediatric Dentistry, Faculty of Dental Medicine, Universitas Airlangga Surabaya. Jl. Mayjend Prof Dr Moestopo, No 47, Surabaya 60132, Indonesia. Email: tania-s@fkg.unair.ac.id

\section{INTRODUCTION}

Down Syndrome is a genetic disorder caused by the presence of 47 chromosomes, with trisomy 21 chromosomes. Chromosome 21 trisomy causes structural and functional anomalies of the body system and limited intelligence conditions. ${ }^{1}$ Children and adolescents with Down Syndrome have characteristics of learning difficulties, difficulty in speech and language, difficulty in concentrating, and difficulties in fine and gross motor skills. ${ }^{2}$ According to the World Health Organization (WHO), the prevalence of Down Syndrome children in the world is estimated to be between 1 in 1,000 to 1 of 1,100 births and every year around 3000 to 5000 children are born with this genetic disorder. In Indonesia, the incidence of Down Syndrome children is $3.3 \%{ }^{3}$ Down Syndrome has significant problems with the integration of sensory information and coordination of motor output. ${ }^{4}$ Down Syndrome children also experience memory deficits, especially information that is displayed verbally. ${ }^{5}$ Some activities must be given the repetition of instructions because of limited understanding of Down Syndrome children. ${ }^{6}$

In addition, Down Syndrome children have poor oral hygiene. Almost all children with Down Syndrome experience moderate to severe gingivitis with age and the degree of mental limitations. ${ }^{7}$ The prevalence of the occurrence of diseases in the oral cavity such as periodontal disease in Down Syndrome children is higher than in normal children due to lack of skills in cleaning the oral cavity. ${ }^{8}$ As many as $55 \%$ of Down Syndrome children experience gingivitis and $45 \%$ of Down Syndrome children experience periodontitis. Some individuals with Down Syndrome have 
difficulty in maintaining oral hygiene and brushing their teeth so that they need help in brushing and flossing. ${ }^{9}$

A toothbrush is a tool to clean the oral cavity. The benefits of brushing teeth are to clean teeth from food scraps, help prevent plaque formation and clean plaque. ${ }^{10} \mathrm{An}$ electric toothbrush or commonly referred to as an automatic toothbrush is an electric or battery-powered toothbrush, revealed that using an electric toothbrush in children with mental limitations was significantly more effective in reducing the plaque index. The use of electric toothbrushes in children with mental disabilities is a good in reducing the plaque index and gingivitis index and helps them ease when brushing their teeth. ${ }^{11}$ According to electric toothbrushes have the advantage of removing plaque. It is expected that if the plaque index falls, oral hygiene is better. ${ }^{12}$

Although Down Syndrome children have intellectual and verbal communication limitations, they have more ability to capture instructions visually. They are easier to learn using the demonstration method. The instructions presented visually together with verbal explanations will make it easier for them to capture information. ${ }^{13}$ Audiovisual learning methods are also appropriate to be applied to Down Syndrome children because the media can stimulate the senses of sight and hearing by projecting moving images and sounds such as animated videos and television so that it can attract the attention of children. ${ }^{14}$

Based on the condition of children with Down Syndrome and efforts to improve the oral hygiene of Down Syndrome children, the researchers wanted to know the effectiveness of using manual and electric toothbrushes and the effect of brushing education with animated videos on OHI-S in children with Down Syndrome when compared with the manual method with the help of dental phantom.

\section{MATERIALS AND METHODS}

The study was done in Pediatric Dentistry Specialist Clinic of Dental and Oral Hospital of Universitas Airlangga, obtained subjects of 34 children with Down Syndrome in accordance with predetermined criteria. Types of toothbrushes used are manual toothbrushes and electric toothbrushes. The selected manual toothbrush is a special toothbrush for children with soft bristle brushes, while the electric toothbrush chosen is an electric toothbrush for children with battery energy. The subjects will be divided into two groups, namely the manual toothbrush group and the electric toothbrush group. The ability of a Down Syndrome child to be able to do activities independently such as dressing, eating and cleaning themselves were grouped into electric toothbrush groups. Subjects of Down Syndrome children were divided into two groups namely group A to brush their teeth using an electric toothbrush and group B to brush their teeth using a manual toothbrush.

Tooth brushing education was accompanied by parents. The media used for education is to use a cartoon type animated video with a sound duration of 2 minutes that attracts the attention of Down Syndrome children. After being educated, Down Syndrome children practice the right way to brush their teeth.

OHI-S is a measurement to evaluate oral hygiene. The index measures six teeth, namely teeth $16,11,26,46,31$, and 36. After being irrigated and teeth dried, then examined and recorded the location of debris and calculus on the tooth surface. Each surface is given an index of 0 to 3 . The index is then added up and divided by the total number of teeth examined.

\section{RESULTS}

From the table, there was a tendency for differences in OHI-S scores before and after tooth brushing in groups A and $\mathrm{B}$ (Table 1). The division of the number of children in groups $\mathrm{A}$ and $\mathrm{B}$ was done by dividing the total number of subjects in two so that group $\mathrm{A}$ is obtained by 17 subjects and group B by 17 subjects. However, at the time of examination, some children who were not cooperative and not trainable in group A who were supposed to brush their teeth using electric toothbrushes were grouped in group B using manual toothbrushes so that group A had 12 children and group B had 22 children.

Groups A and B show a decrease in OHI-S scores after brushing teeth. However, in group A, a decrease in OHI-S score was greater than the decrease in OHI-S score in group B. The measurement results obtained were then analyzed statistically. The first test carried out was a statistical test to compare OHI-S scores before and after brushing teeth in groups A and B (Table 2).

From the normality test, the OHI-S score before and after tooth brushing in group A and group B results $\mathrm{p}>0.05$ so that this data was normally distributed. The statistical test performed for normal distribution data is the paired t-test sample test. In group A, the paired t-test sample was tested, there was a significant difference in the OHI-S score ( $p$ $<0.05$ ) between before brushing and after brushing with an electric toothbrush. Then in group B, a statistical test using paired t-test showed that there was no significant difference in the OHI-S score $(p>0.05)$ between before brushing teeth and after brushing teeth using manual toothbrushes, which means brushing teeth using a manual toothbrush on OHI-S scores before and after Down Syndrome children did not give statistically different results. To measure the difference between subject groups (group A and group B) the first normality test was done using the Kolmogorov-Smirnov test to find out data on normal distribution or not normal distribution.

From the normality test, the OHI-S score after brushing teeth in groups $\mathrm{A}$ and $\mathrm{B}$ obtained $\mathrm{p}>0.05$, which means that the data was normally distributed. Therefore, the statistical test used to test the differences between the two subject groups is the Independent T-test (Table 3). The results of the Independent T-test, the OHI-S score of children with Down Syndrome after brushing their teeth in groups A and B showed there was no significant difference $(p>0.05)$ which means that after brushing their teeth using an electric 
toothbrush and manual toothbrushes do not give results statistically different.

The 34-education using animated videos and group II for manual education using a dental phantom. The division of the number of children in groups I and II was done by dividing the two groups equally. Group I and II both 17 children. However, at the time of education, some children who were less cooperative and should have received manual education with dental phantom were transferred to education using animated videos so that group I had 21 children and group II had 13 children (Table 4).

Group I and II show a decrease in OHI-S scores after education. However, in group I there was a greater decrease compared to the decrease in group II. The measurement results obtained are then analyzed statistically. The first test conducted was a statistical test to compare OHI-S scores before and after education with animated videos (group I) and dental phantom (group II) (Table 5).
From the normality test that has been done, the OHI-S score in group I both before and after education is obtained the value of $\mathrm{p}<0.05$ which means the data was not normally distributed, so the statistical test that can be used was the Wilcoxon test. While the OHI-S scores in group II before and after education obtained the results of $\mathrm{p}>0.05$, which means that the data distribution was normal, so the statistical test used was paired sample t-test.

In group I a statistical test was performed using the Wilcoxon test, there was a significant difference in the OHI-S score $(\mathrm{p}<0.05)$ in group I before and after being educated. Then in group II, a statistical test using paired t-test showed no significant difference $(p>0.05)$ between before and after education which means the method did not give statistically different results.

To measure the difference between the two subject groups (groups I and II) a normality test was carried out using Kolmogorov - Smirnov. From the normality test

Table 1. The average OHI-S scores of Down Syndrome children before and after tooth brushing in groups A and B

\begin{tabular}{lcccc}
\hline & \multicolumn{2}{c}{ Group A (12) } & \multicolumn{2}{c}{ Group B (22) } \\
\cline { 2 - 6 } & OHI-S Pre-Toothbrush & OHI-S Post Toothbrush & OHI-S Pre-Toothbrush & OHI-S Post Toothbrush \\
\hline $\begin{array}{l}\text { Average (mean) } \\
\text { Difference in average }\end{array}$ & 2.04 & 0.44 & 1.34 & 0.65 \\
Std. Deviation & 0.91 & 1.6 & & 0.69 \\
\hline
\end{tabular}

Table 2. Statistical tests on the OHI-S scores of groups A and B

\begin{tabular}{lccc}
\hline Treatment & Time & P. & Sig (2-tailed) \\
\hline \multirow{2}{*}{ Group A } & Before & 0.34 & 0.02 \\
& After & 0.79 & \\
\hline \multirow{2}{*}{ Group B } & Before & 0.73 & 0.40 \\
\hline
\end{tabular}

Table 3. Independent T-test results on OHI-S scores after toothbrushing in groups A and B

\begin{tabular}{lcc}
\hline & The mean & Sig (2-tailed) \\
\hline Group A & 0.44 & 0.51 \\
Group B & 0.65 & \\
\hline
\end{tabular}

Table 4. The average OHI-S scores of children with Down Syndrome group I before and after being educated

\begin{tabular}{lllll}
\hline & & Group I (21) & Group II (13) \\
\hline & OHI-S Pre-Education & OHI-S Post Education & OHI-S Pre-Education & OHI-S Post Education \\
\hline (Mean) & 1.2 & 0.4 & 1.25 & 0.57 \\
Difference in average & 0.8 & & 0.68 & \\
Standard deviation & 1.00 & 0.55 & 0.66 & 0.49 \\
\hline
\end{tabular}

Table 5. Statistical tests on OHI-S scores of groups I and II

\begin{tabular}{lccc}
\hline Group & Treatment Time & P. & Sig (2-tailed) \\
\hline \multirow{2}{*}{ Group I } & Before Education & 0.040 & \multirow{2}{*}{0.004} \\
& After Education & 0.002 & \\
\multirow{2}{*}{ Group II } & Before Education & 0.244 & \multirow{2}{*}{0.646} \\
\hline
\end{tabular}

Table 6. Mann-Whitney test results in groups I and II against OHI-S scores after education

\begin{tabular}{lcc}
\hline Treatment & The mean & Sig (2-tailed) \\
\hline Group I & 16.38 & 0.390 \\
Group II & 19.31 & \\
\hline
\end{tabular}


that has been done, OHI-S scores after being educated in groups I and II obtained $p$ values $<0.05$ so that this data was not normally distributed. Therefore, the statistical test that can be used is the Mann-Whitney test (Table 6). From Mann-Whitney test, the OHI-S scores of groups I and II after being educated showed no significant difference $(\mathrm{p}>$ $0.05)$ which means the method did not give statistically different results.

\section{DISCUSSION}

Down Syndrome was a genetic disorder that occurs in children caused by the presence of chromosome trisomy 21. ${ }^{15}$ Children with Down Syndrome have limitations and delays in motor and intellectual development so they have difficulty in caring for themselves and tend to have a dependency on their environment, especially their families. ${ }^{15}$

In group A, there was a significant difference between OHI-S scores before and after brushing with an electric toothbrush $(p<0.05)$. This was because electric toothbrushes can attract the attention of children with Down Syndrome so they want to brush their teeth using an electric toothbrush because it has a variety of colors and images with a handle that was comfortable to hold and easy to control, especially children with Down Syndrome who have lower muscle performance because they have muscle hypotonia congenital. ${ }^{11,12,16,17}$ The advantage of an electric toothbrush is that it is easier to remove plaque through the automatic oscillation of the toothbrush head and prevent gingivitis because the pressure sensor possessed by an electric toothbrush can be regulated thereby reducing enamel and gingival damage. ${ }^{11,12,16,17}$ Oscillation and rotation of electric toothbrushes are more effective in removing plaque than manual toothbrushes. ${ }^{18}$ Electric toothbrushes more easily remove plaque and reduce the risk of gingival damage at first use because it is easy to control and the effect of learning to brush teeth properly through an electric toothbrush is more evident in Down Syndrome children. ${ }^{16}$

In group B, different results from group A were obtained; statistical tests showed that there was no significant differences between OHI-S scores before and after tooth brushing using manual toothbrushes. This is because the effectiveness of manual toothbrushes is still limited by the motor abilities and skills of users, especially for children with Down Syndrome which incidentally has lower motor performance than other children due to congenital muscle hypotonia. $^{18}$

However, the results of statistical tests showed no significant difference in the OHI-S score of children with Down Syndrome between group A and group B ( $p>0.05)$. This is because sampling is purposively resulting in the wide age range of the subject obtained, aged 6 to 19 years, and the absence of information about IQ in each subject causes the subject cannot be grouped based on IQ so that all subjects are given brushing education in a way that was similar. However, after conducting the study, the number of subjects in group B became more $(n=22)$ compared to group A ( $n$ $=12$ ). Although initially the total number of subjects was divided equally (group A numbered 17 children and group B totaled 17 children), at the time of the study not all subjects in group A that were supposed to brush their teeth using electric toothbrushes could do well (not trainable). So for the subject that was not trainable from group A, it was moved to group B which causes the number of subject group B to be 22 children while group $\mathrm{A}$ is 12 children. This condition is explained that some children with special needs such as Down Syndrome children cannot adapt to the movements, vibrations and sounds of an electric toothbrush so that they feel scared or anxious. ${ }^{19}$ However, Dash ${ }^{15}$ states that children with Down Syndrome who are trainable can speak clearly, can receive training or education and can imitate what is taught. In addition, children with Down Syndrome have a very good ability to mimic movements that are demonstrated or called imitates well. ${ }^{13}$

Various long-term and short-term studies comparing the results of electric toothbrushes and manual toothbrushes in children with special needs still find mixed results. Some studies claim that electric toothbrushes are superior to manual toothbrushes, while there are those who claim that electric toothbrushes and manual toothbrushes are as effective. Vibhute and Vandana ${ }^{20}$ state that there was no significant difference between electric toothbrushes and manual toothbrushes. Yaacob et al. ${ }^{21}$ in their review found that electric toothbrushes were more effective in reducing plaque and gingivitis compared to manual toothbrushes.

Children with Down Syndrome require structured and directive early intervention procedures to balance their social and learning abilities. ${ }^{22}$ The use of audio-visual education media with attractive and moving images as educational media stimulates many senses so that more information will be obtained and understood. ${ }^{14}$

Statistical tests showed a significant difference in OHI-S scores $(\mathrm{p}<0.05)$ before and after education was given to group I with the educational method using a 2-minute animated video. Animated video is a form of audio-visual media that combines moving images and sounds that can stimulate children's eyesight and hearing. The advantage of using animated video is that it can attract interest and attention because of the sound and moving images, is more easily accepted and remembered by children, can be played repeatedly, and is effective in a short time..$^{23}$

Different results were shown in group II namely the educational method of brushing teeth using phantom by dentists showed no significant difference $(p>0.05)$ which means the method did not give statistically different results. This is possible because Down Syndrome children often experience memory deficits, especially for information that is displayed verbally. Children with Down Syndrome also have difficulty following instructions and express their thoughts or needs clearly verbally. ${ }^{5}$

However, the results of the study showed no significant differences between the two groups. This is because sampling is purposively resulting in the wide age range of the subjects obtained, aged 6 years to 19 years. The 
lack of information about the IQ of each subject makes it impossible to do groupings based on IQ, so all subjects are given education in the same way regardless of how well their abilities are receiving education. However, after conducting research, the number of subjects became more in group I $(\mathrm{n}=21)$ when compared to group II $(\mathrm{n}=13)$. Although from the beginning the treatment of the subject was evenly divided (group I numbered 17 children and group II numbered 17 children), at the time of the study not all subjects could receive manual education with dental phantom. Subjects that cannot be given manual education with dental phantom are diverted to receive education by using animated videos which causes the number of subjects in group I to be more than in group II. This condition can be explained by the theory of Febriany et al. ${ }^{13}$ that the Down Syndrome children are visual learners, which means they are easier to learn with demonstration methods than through verbal instructions. Information presented visually that is interesting with moving and colour images together with verbal explanations will be easier to understand. In addition, Down Syndrome children have the characteristic of imitates well, which is a very good ability to mimic the movements that are demonstrated repeatedly.

\section{CONCLUSION}

Based on the results of research that has been done about the effectiveness of manual toothbrushes and electric toothbrushes on OHI-S scores of children with Down syndrome, it can be concluded that there is no significant difference in the results of OHI-S score measurements after brushing using manual toothbrushes and electric toothbrushes. Electric toothbrushes and manual toothbrushes have the same effect on decreasing the OHI-S score of children with Down Syndrome. While the results of research that has been done about the effect of brushing education with animated videos on OHI-S scores of Down Syndrome children can be concluded that there is no significant difference in the results of OHI-S score measurements after being educated with animated videos and phantom.

\section{ACKNOWLEDGMENTS}

This study was funded by Ministry of Research Technology and Higher Education of the Republic of Indonesia.

\section{REFERENCES}

1. Wajuihian SO. Down syndrome: An overview. African Vis Eye Heal. 2016 Mar 24;75(1).

2. Patel L, Wolter-Warmerdam K, Leifer N, Hickey F. Behavioral Characteristics of Individuals with Down Syndrome. J Ment Health Res Intellect Disabil. 2018 Jul 3;11(3):221-46.

3. Badan Penelitian dan Pengembangan Kesehatan, RI KK. Riset Kesehatan Dasar. Jakarta: Kementerian Kesehatan Republik Indonesia; 2013.
4. Richard N. The Down's Syndrome Handbook: The Practical Handbook for Parents and Carers. London: Random House UK Ltd; 2011.

5. Rina AP. Meningkatkan Life Skill pada Anak Down Syndrome dengan Teknik Modelling. Pers Psikol Indones. 2016 Sep 11;5(03):215-25.

6. Wiranto. Perancangan Animasi Bertema Daily Living Skills Untuk Anak Down Syndrome Menggunakan Jurnal Desain Idea. 2011.

7. Porovic S, Zukanovic A, Juric H, Dinarevic SM. Oral Health Of Down Syndrome Children In Bosnia And Herzegovina. Mater Sociomed. 2016 Oct;28(5):370-2.

8. Stefanini M, Sangiorgi M, Roncati M, D’Alessandro G, Piana G. Effect on plaque control in children patients with Down syndrome using Digital Brush with or without chlorhexidine: a randomized clinical trial. Spec care Dent. 2015;36(2):66-70.

9. Karimi M. What Should be Done for Dental Care in Down's Syndrome Children? EC Dent Sci. 2019;3:430.

10. Gunjan K, Jalaluddin, Kumar SD. Tooth Brush and Brushing Technique. J Adv Med. 2013;2(1).

11. Amol J, Hegde SS, Ravi S. Comparison of Powered Toothbrush With or Without Parental Assistance With Manual Toothbrush on Plaque and Gingivitis in Mentally Challenged Children of 12-18 Years in Pune, India. J Pakistan Dent Assos. 2013;22(1):42-6.

12. Atarbashi MF, Atarbashi MS. Tooth Brushing in Children. J Dent Mater Tech. 2018;7(4):181-4.

13. Florensia F, K L, Wardani, Taufan RM. Perancangan Interior Creative Center untuk Anak Down Syndrome di Surabaya. J Intra. 2018;6(2):586-99.

14. Mubarak, Wahit I, Nurul C, Rozikin SK. Promosi Kesehatan sebuah pengantar proses belajar mengajar dalam pendidikan. Yogyakarta: Graha Ilmu; 2007.

15. Katrina D, Janet G. Down syndrome: An integrative review. J Neonatal Nurs. 2018;24(5):235-41.

16. Lazarescu D, Boccaneala S, Illiescu A, De Boever JA. Efficacy of plaque removal and learning effect of a powered and a manual toothbrush. J Clin Periodontol. 2003 Aug;30(8):726-31.

17. Sheikh-Al-Eslamian SM, Youssefi N, Seyed Monir SE, Kadkhodazadeh M. Comparison of Manual and Electric Toothbrush in Dental Plaque Removal: A Clinical Trial. Avicenna J Dent Res. 2014 Jun 25;6(1):5-9.

18. Pizzo G, Licata ME, Pizzo I, D’Angelo M. Plaque removal efficacy of power and manual toothbrushes: a comparative study. Clin Oral Investig. 2010 Aug;14(4):375-81.

19. Zhou N, Wong HM, Wen YF, McGrath C. Efficacy of caries and gingivitis prevention strategies among children and adolescents with intellectual disabilities: a systematic review and meta-analysis. J Intellect Disabil Res. 2019;63(6): 507-18.

20. Vibhute A, Vandana KL. The effectiveness of manual versus powered toothbrushes for plaque removal and gingival health: A meta-analysis. J Indian Soc Periodontol. 2012 Apr;16(2):156-60.

21. Yaacob M, Worthington $\mathrm{H}$ V, Deacon SA, Deery C, Walmsley AD, Robinson PG, et al. Powered versus manual toothbrushing for oral health. Cochrane Database Syst Rev. 2014 Jun 17;

22. Karaaslan O, Mahoney G. Effectiveness of Responsive Teaching With Children With Down Syndrome. Intellect Dev Disabil. 2013 Dec 1;51(6):458-69.

23. Notoatmodjo S. Promosi Kesehatan Teori dan Aplikasi. Jakarta: Rineka Cipta; 2010. 